\title{
Adjuvant Whole Breast Radiotherapy Improve Survival in Women with Heart Failure with Reduced Ejection Fraction Receiving Breast-Conserving Surgery
}

\author{
Jiaqiang Zhang \\ Zhengzhou University \\ Shao-Yin Sum \\ Lo-Hsu Medical Foundation Lotung Poh-Ai Hospital \\ Jeng-Guan Hsu \\ Fu Jen Catholic University \\ Ming-Feng Chiang \\ Lo-Hsu Medical Foundation Lotung Poh-Ai Hospital \\ Tian-Shyug Lee \\ Fu Jen Catholic University \\ Szu-Yuan Wu ( $\nabla$ szuyuanwu5399@gmail.com ) \\ Taipei Medical University College of Medicine https://orcid.org/0000-0001-5637-558X
}

\section{Research article}

Keywords: breast cancer, radiotherapy-related cardiotoxicity, breast-conserving surgery, radiotherapy, survival

Posted Date: November 23rd, 2021

DOI: https://doi.org/10.21203/rs.3.rs-987933/v1

License: (c) (i) This work is licensed under a Creative Commons Attribution 4.0 International License. Read Full License

Version of Record: A version of this preprint was published at Journal of Personalized Medicine on December 13th, 2021. See the published version at https://doi.org/10.3390/jpm11121358. 


\section{Abstract}

BACKGROUND: To date, no data on the effect of adjuvant whole breast radiotherapy (WBRT) on oncologic outcomes, such as all-cause death, locoregional recurrence (LRR), and distant metastasis (DM), are available in women with left-side breast intraductal carcinoma (IDC) and heart failure with reduced ejection fraction (HFrEF).

PATIENTS AND METHODS: We enrolled 294 women with left-breast IDC at clinical stages IA-IIIC and HFrEF receiving breastconserving surgery (BCS) followed by adjuvant WBRT or non-adjuvant WBRT. We categorized them into two groups based on their adjuvant WBRT status and compared their overall survival (OS), LRR, and DM outcomes. We calculated the propensity score and applied inverse probability of treatment weighting (IPTW) to create a pseudo-study cohort. Furthermore, we performed a multivariate analysis of the propensity score-weighted population to obtain hazard ratios (HRs).

RESULTS: In the IPTW-adjusted model, adjuvant WBRT (adjusted HR [aHR]: 0.58; 95\% confidence interval [Cl]: 0.33-1.00) was a significant independent prognostic factor for all-cause death $(P=0.0494)$, and the aHR $(95 \% \mathrm{Cl})$ of LRR and DM for adjuvant WBRT was $0.25(0.10-0.62 ; P=0.0028)$ and $0.29(0.14-0.60 ; P=0.0007)$, respectively, compared with the nonadjuvant WBRT group.

CONCLUSION: Adjuvant WBRT was associated with a decrease in all-cause death, LRR, and DM in women with left IDC and HFrEF compared with nonadjuvant WBRT.

\section{Introduction}

Cardiovascular disease may be a complication of breast radiotherapy (RT) and the use of specific systemic agents in the treatment of breast cancer.[1] Incidental radiation to the heart as part of the initial treatment for breast cancer can result in a range of cardiotoxic effects, including coronary artery disease, cardiomyopathy, pericardial disease, valvular dysfunction, and conduction abnormalities.[2-4] At present, no recommended minimum radiation dose that is completely safe exists.[3] RT-related cardiotoxicity (RICT) is associated with a portion of the heart being placed in a radiation field.[1] For all patients with left-sided breast cancers, careful treatment planning is critical to minimize cardiac exposure to radiation.[1]

The association of RT with cardiotoxicity is not dependent on the presence or absence of a breast but on the volume of radiation to the heart.[3, 4] Thus, cardiotoxicities associated with RT differ between the postlumpectomy and postmastectomy settings; this is because in the postmastectomy setting, the RT field often includes the nodal tissues, and these nodes are not always targeted in the postlumpectomy setting. $[5,6]$ Thus, postmastectomy RT is more often associated with cardiac disease relative to postlumpectomy RT, but this is likely a result of the usually larger irradiated volumes of the heart in postmastectomy RT. $[5,6]$ Therefore, RICT in patients with breast cancer should be minimized by using different surgical techniques of breastconserving surgery (BCS) and total mastectomy (TM).

Another crucial issue is whether adjuvant whole breast RT (WBRT) can be safely given to women with heart failure (HF) and leftside breast cancer who receive BCS. No data are available to address the value of adjuvant WBRT in women with breast cancer and HF receiving BCS. HF due to left ventricle (LV) dysfunction is categorized according to LV ejection fraction (LVEF) as HF with reduced ejection fraction (LVEF $\leq 40 \%$, known as HFrEF).[7-9] Until now, no study has estimated the oncologic outcomes of adjuvant WBRT in women with breast intraductal carcinoma (IDC) and HFrEF receiving BCS.

\section{Patients And Methods}

\section{Study population}

In this cohort study, data were retrieved from the Taiwan Cancer Registry Database (TCRD). We enrolled women with HF with reduced ejection fraction (LVEF $\leq 40 \%$; HFrEF) [7-9] who had received a diagnosis of left-side breast IDC between January 1 , 2008, and December 31, 2018. The index date was the date of BCS, and the follow-up duration was from the index date to December 31, 2019. The TCRD of the Collaboration Center of Health Information Application contains detailed cancer-related 
information of patients, including their clinical stage, pathologic stages, chemotherapy regimens, dose of chemotherapy, molecular status, drug use, hormone receptor status, radiation modalities and doses, and surgical procedures.[10-13] The study protocols were reviewed and approved by the Institutional Review Board of Tzu-Chi Medical Foundation (IRB109-015-B).

\section{Inclusion and exclusion criteria}

The diagnoses of the enrolled patients with HFrEF were confirmed after their pathological data were reviewed, and the women with newly diagnosed left-side IDC were confirmed to have no other cancers or distant metastases. The women with HFrEF were included if they had received a left-side IDC diagnosis, were 20 years old or older, and had clinical stage IA-IIIC (American Joint Committee on Cancer [AJCC], 8th edition) without metastasis. Patients with HFrEF were excluded if they had a history of cancer before the IDC diagnosis date, unknown pathologic types, missing sex data, unclear staging, or non-IDC histology. In addition, patients undergoing neoadjuvant chemotherapy or with unclear differentiation of tumor grade, missing HR status, missing data on trastuzumab or anthracycline use, or unclear staging were excluded. Other adjuvant treatments such as adjuvant chemotherapy, hormone therapy, or the human epidermal growth factor receptor 2 inhibitors did not constitute exclusion criteria based on the National Comprehensive Cancer Network (NCCN) guidelines.[14] We also excluded patients with HFrEF with unclear data on surgical procedures such as BCS or TM, ill-defined nodal surgery, unclear Charlson comorbidity index $(\mathrm{CCl})$, or unclear differentiation from our cohort. Hormone receptor positivity was defined as $\geq 1 \%$ of tumor cells demonstrating positive nuclear staining through immunohistochemistry.[15]

After applying the inclusion and exclusion criteria, we enrolled 294 women with HFrEF and AJCC clinical stage IA-IIIC and leftside IDC who had received a BCS followed by sentinel lymph node biopsy (SLNB) or axillary lymph node dissection (ALND) and divided them into two groups based on their adjuvant WBRT status to compare all-cause mortality: Group 1 (women with left-side IDC and HFrEF who received BCS followed by adjuvant WBRT) and Group 2 (women with left-side IDC and HFrEF who received BCS and no adjuvant WBRT). We also excluded women in Group 1 receiving nonstandard adjuvant WBRT (contrast with standard adjuvant radiotherapy consisting of irradiation to the whole breast with a minimum of 50 Gy). Contemporary RT techniques were included in our study and the conventional two-dimensional RT technique was excluded. The included contemporary RT techniques were three-dimensional RT and intensity-modulated radiation therapy. The incidence of comorbidities was scored using the CCI.[16, 17] Ischemic heart disease, heart valvular disease, cardiomyopathy, hypertension, diabetes, and arrhythmias and conduction disorders were excluded from the $\mathrm{CCl}$ scores to avoid repetitive adjustment in multivariate analysis. Only comorbidities observed within 6 months before the index date were included; they were coded and classified according to the International Classification of Diseases, 10th Revision, Clinical Modification (ICD-10-CM) codes at the first admission or based on more than two repetitions of a code issued at outpatient department visits.

\section{Study covariates and statistical analysis}

Significant independent predictors, namely age, diagnosis year, CCl score, differentiation, $\mathrm{pT}$, pN, hypertension, ischemic heart disease, heart valvular disease, cardiomyopathy, arrhythmias and conduction disorders, diabetes, adjuvant chemotherapy with anthracycline-based regimen, hormone receptor status, trastuzumab use, nodal surgery, hospital level (academic or nonacademic), and income, were analyzed using a multivariate analysis of the propensity score-weighted population to determine hazard ratios (HRs). We calculated the propensity score and applied inverse probability of treatment weighting (IPTW) to create a pseudo-study cohort; the weighted cohort avoids covariate bias and mimics randomized adjuvant WBRT or no adjuvant WBRT assignment: IPTW for patients with WBRT = 1/p(WBRT); IPTW for patients without WBRT = 1/(1 - p[WBRT]). $[18,19]$ The independent predictors were examined in multivariable analyses after IPTW adjustment. Moreover, they were controlled for and were stratified in the analysis. The endpoint was all-cause death in the women with left-side IDC and HFrEF who received BCS followed by adjuvant WBRT (Group 1, case group) and in the women with left IDC and HFrEF who received BCS and had no adjuvant WBRT (Group 2, control group).

The cumulative incidence of death was estimated using the Kaplan-Meier method, and differences in the overall survival (OS), locoregional recurrence (LRR)-free survival, and distant metastasis (DM)-free survival between women with left IDC and HFrEF 
receiving BCS followed by adjuvant WBRT versus no adjuvant WBRT were determined using a log-rank test. After confounders were adjusted for, IPTW-adjusted models were used to determine the time from the index date to all-cause mortality in the women with left IDC and HFrEF who received BCS followed by adjuvant WBRT or no adjuvant WBRT. Subsequently, in a multivariate analysis, HRs were adjusted for age, diagnosis year, $\mathrm{CCl}$ scores, differentiation, $\mathrm{pT}$, pN, hypertension, ischemic heart disease, heart valvular disease, cardiomyopathy, arrhythmias and conduction disorders, diabetes, adjuvant chemotherapy with anthracycline, hormone receptor status, trastuzumab use, nodal surgery, hospital levels, and incomes. All analyses were conducted using SAS (Version 9.3; SAS, Cary, NC, USA), and a two-tailed $P$ value $<0.05$ was considered statistically significant.

\section{Results}

\section{Study cohort}

We enrolled 294 women with left-breast IDC at clinical stages IA-IIIC and HFrEF who received BCS followed by adjuvant WBRT or no adjuvant WBRT (Table 1). Among these women, 223 with left IDC and HFrEF received BCS followed by adjuvant WBRT (Group 1) and 71 with left IDC and HFrEF received BCS with no adjuvant WBRT (Group 2). After IPTW was executed using the propensity score, the covariates between Groups 1 and 2 were found to be homogenous. The median follow-up durations after the index date were 6.96 and 5.09 years for women with left IDC and HFrEF who received BCS followed by adjuvant WBRT or no adjuvant WBRT, respectively. All standardized differences in covariates were smaller than 0.1 (Table 1) and were homogenous between the two groups.

\section{Effects of adjuvant WBRT on oncologic outcomes in women with left- side IDC and HFrEF receiving BCS}

IPTW-adjusted models indicated that adjuvant WBRT was a significantly better independent prognostic factor for OS, LRR, and DM in the women with left IDC and HFrEF receiving BCS (Table 2). Adjuvant WBRT (adjusted HR [aHR]: 0.58; $95 \%$ confidence interval [Cl]: 0.33-1.00) was a significant independent prognostic factor for all-cause death $(P=0.0494 ;$ Table 2$)$. In the IPTWadjusted model, the aHR $(95 \% \mathrm{Cl})$ for LRR in the adjuvant WBRT group was $0.25(0.10-0.62 ; P=0.0028$; Table 2$)$ compared with the no adjuvant WBRT group. Moreover, the aHR $(95 \% \mathrm{Cls})$ for DM in the adjuvant WBRT group was $0.29(0.14-0.60 ; P=$ 0.0007) compared with the no adjuvant WBRT group (Table 2).

\section{Other independent predictors of all-cause death, LRR, and DM in the women with left IDC and HFrEF receiving BCS}

Old age (>65 years), $\mathrm{CCl} \geq 1$, advanced $\mathrm{pT}$ stages (pT2-4), advanced pN stages (pN1-3), hormone receptor negative status, and differentiation Grade II and III were identified as crucial independent poor prognostic factors for OS (Tables 2). IPTWadjusted models were adjusted for age, diagnosis year, $\mathrm{CCl}$ score, differentiation, $\mathrm{pT}$, pN, hypertension, ischemic heart disease, heart valvular disease, cardiomyopathy, arrhythmias and conduction disorders, diabetes, adjuvant chemotherapy with anthracycline-based regimen, hormone receptor status, trastuzumab use, nodal surgery, hospital level, and income; the aHRs $(95 \% \mathrm{Cls})$ of all-cause death for age $>65$ years, $\mathrm{CCl} \geq 1$, pT2-4, pN1-3, differentiation Grades II and III, and hormone receptor positive status were 1.34 (1.18-3.26), 1.14 (1.08-1.72), 1.33 (1.05-2.34), 2.48 (1.37-4.47), 1.58 (1.15-2.17), 1.73 (1.26-2.36), and $0.68(0.52-0.88)$ compared with age $20-65$ years, $\mathrm{CCl}=0, \mathrm{pT} 1, \mathrm{pN}$, differentiation grade $\mathrm{l}$, and hormone receptor negative status, respectively (Table 2). IPTW-adjusted models also revealed the aHRs ( $95 \% \mathrm{Cls}$ ) of LRR for pT2-4, pN1-3, differentiation grade II, differentiation grade III, and hormone receptor positive status to be 1.73 (1.01-1.71), 1.82 (1.43-4.53), 2.06 (1.713.27), 2.16 (1.89-3.46), and $0.66(0.50-0.86)$ compared with $\mathrm{pT} 1, \mathrm{pN} 0$, differentiation grade $\mathrm{l}$, and hormone receptor negative status, respectively. Moreover, the aHRs (95\% Cls) of DM for pN1-3, differentiation grade II, differentiation grade III, and hormone receptor positive status were 1.75 (1.31-2.84), 2.02 (1.58-3.04), 2.94 (1.69-3.61), and 0.59 (0.32-0.75) compared with pN0, differentiation grade $\mathrm{l}$, and hormone receptor negative status, respectively. 


\section{Survival curves of adjuvant WBRT or no adjuvant WBRT in women with left IDC and HFrEF receiving BCS}

Figure 1 presents Kaplan-Meier curves that illustrate the OS of the women with left IDC and HFrEF receiving BCS with adjuvant WBRT or no adjuvant WBRT. The 5-year overall survival rates were $86.47 \%$ and $75.92 \%$ in the adjuvant WBRT and no adjuvant WBRT groups, respectively (Figure 1); the OS rate was associated with an increasing trend in the adjuvant WBRT group (log-rank test, $P=0.0618$ ) compared with the non-WBRT group. Additionally, the 5-year LRR-free survival in women with left IDC and HFrEF receiving BCS was $95.78 \%$ and $86.11 \%$ in the adjuvant WBRT group and no adjuvant WBRT group, respectively (Figure 2; log-rank test, $P=0.0083$ ). The 5-year DM-free survival in women with left IDC and HFrEF receiving BCS was $96.23 \%$ and $78.33 \%$ in the adjuvant WBRT group and no adjuvant WBRT group, respectively (Figure 3; log-rank test, $P=0.0027$ ).

\section{Discussion}

The use of RT has contributed to significant improvements in disease-specific survival among patients with early stage breast cancer.[20] The success of RT, used either alone or in combination with other modalities, has resulted in large cohorts of breast cancer survivors who are vulnerable to late complications such as RICT from RT.[5, 21-27] Numerous treatment-related factors are responsible for cardiotoxicity in women with breast cancer.[28-38] Thus, we conducted the study to determine the survival benefits offered by adjuvant WBRT in women with left-side IDC and HFrEF receiving BCS.

Patients with breast cancer might experience adverse effects from many cardiotoxic treatments such as adjuvant RT, anthracycline-based chemotherapy, or trastuzumab. ${ }^{6}[5,21-38]$ Although cardiovascular diseases such as HF, heart attacks, and stroke remain the leading cause of death in women, many believe breast cancer to be more deadly.[39] In fact, the risk of RICT should be weighed against the potential benefits of adjuvant WBRT with respect to the patients' prognosis and likely clinical benefit.[5, 21-27] Until now, no data have been available for the evaluation of oncologic outcomes (OS, LRR, and DM) of adjuvant WBRT in women with left-side breast IDC and HFrEF receiving BCS. This is the first study to explore the value of adjuvant WBRT for women with left-side breast IDC and HFrEF receiving BCS. As shown in Table 2, adjuvant WBRT resulted in better OS, LRR-free status, and DM-free status compared with no adjuvant WBRT in women with left-side breast IDC and HFrEF receiving BCS. The potential reasons might be the recent decline in mortality in women with HF[40,41] and the advances in contemporary RT techniques with reduced irradiation volumes to the heart.[2, 23, 24]

According to our literature review, this is the first study to estimate the oncologic outcomes of adjuvant WBRT among women with left-side breast IDC and HFrEF receiving BCS. No consensus or evidence for the use of adjuvant WBRT in women with leftside breast IDC and HFrEF receiving BCS is present. In the IPTW-adjusted models, adjuvant WBRT was associated with a decrease in the risk of all-cause death, LRR, and DM among women with left-side breast IDC and HFrEF receiving BCS (Table 2). The improvement in contemporary RT techniques with decreased irradiation doses and decreased volumes to the heart and the long-term improvement in mortality rates in patients with HFrEF over time might have caused the significant beneficial oncologic outcomes of adjuvant WBRT in women with left-side breast IDC and HFrEF receiving BCS.[2, 23, 24] Our study is the first to demonstrate that the potential benefits of adjuvant WBRT with contemporary RT techniques outweigh the risk of RICT given the patients' prognosis and likely long-term OS, LRR, and DM benefits (Table 2). According to our findings, we strongly suggested that women with left-side breast IDC and HFrEF receiving BCS should also receive adjuvant WBRT to decrease the risk of all-cause death, LRR, and DM.

As shown in Table 2, adjuvant WBRT was a significant prognostic factor for OS, LRR, and DM compared with no adjuvant WBRT in women with left-side IDC and HFrEF receiving BCS; moreover, old age (>65 years), CCI $\geq 1$, advanced pT stages (pT2-4), advanced $\mathrm{pN}$ stages ( $\mathrm{pN} 1-3)$, hormone receptor negative status, and differentiation Grade II-III were significant prognostic factors for OS, compatible with findings of previous studies.[10, 11, 42-49] Moreover, advanced pN stages (pN1-3), hormone receptor negative status, and differentiation Grade II-III were significant poor prognostic factors for LRR and DM in women with left-side breast IDC and HFrEF receiving BCS, which is also compatible with findings of previous studies.[10, 11, 42-49] Our findings of prognostic factors for OS, LRR, and DM in women with IDC and HFrEF receiving BCS are similar with those of 
previous studies,[10, 11, 42-49] and no additional prognostic factor has been identified in previous studies other than the ones determined in the current study irrespective of whether underlying HFrEF was present.

A strength of our study was that it was the first cohort study to estimate the survival outcomes of adjuvant WBRT or no adjuvant WBRT among women with left-side IDC and HFrEF receiving BCS. The covariates between the adjuvant WBRT and no adjuvant WBRT groups were homogenous for women with left-side IDC and HFrEF receiving BCS, with no selection bias (Table 1). No study has estimated the effect of adjuvant WBRT on women with left-side IDC and HFrEF receiving BCS. In our study, the poor prognostic factors for OS in women with left-side IDC and HFrEF receiving BCS were old age, $\mathrm{CCl} \geq 1$, advanced pT stages (pT2-4), advanced pN stages (pN1-3), hormone receptor negative status, and differentiation Grade II-III of (Table 2), which are consistent with factors in women with breast cancer without HFrEF reported in previous studies.[45-49] Furthermore, our study is the first to demonstrate the benefits of adjuvant WBRT with contemporary RT techniques for OS, LRR, and DM in women with left-side IDC and HFrEF receiving BCS. Our findings should be considered in future clinical practice and prospective clinical trials. We suggest that adjuvant WBRT is valuable to achieving better outcomes of OS, LRR, and DM in women with left-side IDC and HFrEF receiving BCS.

This study has some limitations. First, because all women with left-side breast IDC and HFrEF were enrolled from an Asian population, the corresponding ethnic susceptibility compared with the non-Asian population remains unclear; hence, our results should be cautiously extrapolated to non-Asian populations. However, no evidence exists as to the differences in oncologic outcomes in Asian versus non-Asian patients with breast IDC and HFrEF receiving BCS. Second, the diagnoses of all comorbid conditions were based on ICD-10-CM codes. However, the combination of Taiwanese TCRD and National Health Insurance Research Database (NHIRD) data appears to be a valid resource for population research on cardiovascular diseases, stroke, or chronic comobidities.[50-52] Moreover, the Taiwan Cancer Registry Administration randomly reviews charts and interviews patients to verify the accuracy of the diagnoses, and hospitals with outlier chargers or practices may be audited and subsequently be heavily penalized if any malpractice or discrepancy is detected. Accordingly, to obtain crucial information on population specificity and disease occurrence, a large-scale randomized trial comparing carefully selected patients undergoing suitable treatments is essential. Finally, the TCRD does not contain information regarding dietary habits or body mass index, which may be risk factors for mortality. Nevertheless, considering the magnitude and statistical significance of the observed effects in this study, these limitations are unlikely to affect the conclusions.

\section{Conclusions}

Adjuvant WBRT was associated with a decrease in all-cause death, LRR, and DM among women with left-side breast IDC and HFrEF compared with no adjuvant WBRT. We suggest adjuvant WBRT for women with left-side IDC receiving BCS, even if they have HFrEF.

\section{Abbreviations}

WBRT, whole breast radiotherapy; LRR, locoregional recurrence; DM, distant metastasis; IDC, intraductal carcinoma; HFrEF, heart failure with reduced ejection fraction; BCS, breast-conserving surgery; OS, overall survival; aHR, adjusted hazard ratio; HR, hazard ratio; IPTW, inverse probability of treatment weighting; Cl, confidence interval; AJCC, American Joint Committee on Cancer; TCRD, Taiwan Cancer Registry Database; SD, standard deviation; Her-2, human epidermal growth factor receptor-2; SLNB, sentinel lymph node biopsy; ALND, axillary lymph node dissection; CKD, chronic kidney disease; CCI, Charlson comorbidity index; ICD-10-CM, International Classification of Diseases, 10th Revision, Clinical Modification; NCCN, National Comprehensive Cancer Network; RT, radiotherapy; RICT, radiotherapy-related cardiotoxicity; TM, total mastectomy; HF, heart failure; LV, left ventricular; LVEF, left ventricular ejection fraction; T, tumor; N, nodal; pT, pathologic tumor stage; pN, pathologic nodal stage; NHIRD, National Health Insurance Research Database

\section{Declarations}




\section{Ethics approval and consent:}

The study protocols were reviewed and approved by the Institutional Review Board of Tzu-Chi Medical Foundation (IRB109-015B).

\section{Consent for publication:}

Not applicable

\section{Availability of data and material:}

The data sets supporting the study conclusions are included in this manuscript and its supplementary files.

\section{For software:}

Project name: Not applicable

Project homepage: Not applicable

Archived version: Not applicable

Operating system(s): Not applicable

Programming language: Not applicable

Other requirements: Not applicable

License: Not applicable

Any restrictions for use by nonacademicians: Not applicable

\section{Competing interests:}

The authors have no potential conflicts of interest to declare. The data sets supporting the study conclusions are included in the manuscript.

\section{Research Funding:}

Lo-Hsu Medical Foundation, LotungPoh-Ai Hospital, supports Szu-Yuan Wu's work (Funding Number: 10908, 10909, 11001, 11002, 11003, 11006, and 11013). Taipei Medical University-Wan Fang Hospital (Funding Number: 107TMU-WFH-08) supports Tsai-Mu Cheng's work.

\section{Author Contributions}

Conception and Design: Jiaqiang Zhang, MD, PhD; Szu-Yuan Wu, MD, MPH, PhD

Financial Support: Lo-Hsu Medical Foundation, LotungPoh-Ai Hospital, supports Szu-Yuan Wu's work (Funding Number: 10908, 10909, 11001, 11002, 11003, 11006, and 11013). Taipei Medical University-Wan Fang Hospital (Funding Number: 107TMUWFH-08) supports Tsai-Mu Cheng's work. 
Collection and Assembly of Data: Jiaqiang Zhang, MD, PhD; Shao-Yin Sum, MD; Szu-Yuan Wu, MD, MPH, PhD

Data Analysis and Interpretation: Jiaqiang Zhang, MD, PhD; Jeng-Guan Hsu, PhD; Ming-Feng Chiang, MD; Tian-Shyug Lee, PhD

Administrative Support: Szu-Yuan Wu*

Manuscript Writing: Jiaqiang Zhang, MD, PhD; Shao-Yin Sum, MD; Ming-Feng Chiang, MD; Szu-Yuan Wu, MD, MPH, PhD

Final Approval of Manuscript: All authors

\section{Key points:}

Question: Is adjuvant whole breast radiotherapy (WBRT) worthy for women with left-side breast intraductal carcinoma (IDC) and heart failure with reduced ejection fraction (HFrEF) receiving breast-conserving surgery (BCS)?

Findings: In the IPTW-adjusted models, adjuvant WBRT was associated with a decrease in all-cause death, LRR, and DM in women with left IDC and HFrEF compared with no adjuvant WBRT.

Meaning: We suggest adjuvant WBRT for women with left-side IDC receiving BCS, even when they have HFrEF.

\section{Acknowledgement}

Access to Data statement: We used data from the National Health Insurance Research Database (NHIRD) and Taiwan Cancer Registry database (TCRD). The authors confirm that, for approved reasons, some access restrictions apply to the data underlying the findings. The data utilized in this study cannot be made available in the manuscript, the supplemental files, or in a public repository due to the "Personal Information Protection Act" executed by Taiwan's government, starting from 2012. Requests for data can be sent as a formal proposal to obtain approval from the ethics review committee of the appropriate governmental department in Taiwan. Specifically, links regarding contact info for which data requests may be sent to are as follows: http://nhird.nhri.org.tw/en/Data_Subsets.html\#S3 and http://nhis.nhri.org.tw/point.html. Szu-Yuan Wu, MD, PhD had full access to all the data in the study and takes responsibility for the integrity of the data and the accuracy of the data analysis.

Role of funder statement: Lo-Hsu Medical Foundation, LotungPoh-Ai Hospital, supports Szu-Yuan Wu's work (Funding Number: $10908,10909,11001,11002,11003,11006$, and 11013) for design and conduct of the study.

\section{References}

1. Hooning MJ, Botma A, Aleman BM, Baaijens MH, Bartelink H, Klijn JG, Taylor CW, van Leeuwen FE. Long-term risk of cardiovascular disease in 10-year survivors of breast cancer. J Natl Cancer Inst. 2007;99(5):365-75.

2. Travis LB, Ng AK, Allan JM, Pui CH, Kennedy AR, Xu XG, Purdy JA, Applegate K, Yahalom J, Constine LS, et al. Second malignant neoplasms and cardiovascular disease following radiotherapy. J Natl Cancer Inst. 2012;104(5):357-70.

3. Moslehi J. The cardiovascular perils of cancer survivorship. N Engl J Med. 2013;368(11):1055-6.

4. Darby SC, Ewertz M, McGale P, Bennet AM, Blom-Goldman U, Bronnum D, Correa C, Cutter D, Gagliardi G, Gigante B, et al. Risk of ischemic heart disease in women after radiotherapy for breast cancer. N Engl J Med. 2013;368(11):987-98.

5. Paszat LF, Mackillop WJ, Groome PA, Schulze K, Holowaty E. Mortality from myocardial infarction following postlumpectomy radiotherapy for breast cancer: a population-based study in Ontario, Canada. Int J Radiat Oncol Biol Phys. 1999;43(4):755-62.

6. Hojris I, Overgaard M, Christensen JJ, Overgaard J. Morbidity and mortality of ischaemic heart disease in high-risk breastcancer patients after adjuvant postmastectomy systemic treatment with or without radiotherapy: analysis of DBCG 82b and $82 \mathrm{c}$ randomised trials. Radiotherapy Committee of the Danish Breast Cancer Cooperative Group. Lancet. 1999;354(9188):1425-30. 
7. Yancy CW, Jessup M, Bozkurt B, Butler J, Casey DE Jr, Drazner MH, Fonarow GC, Geraci SA, Horwich T, Januzzi JL, et al. 2013 ACCF/AHA guideline for the management of heart failure: executive summary: a report of the American College of Cardiology Foundation/American Heart Association Task Force on practice guidelines. Circulation. 2013;128(16):1810-52.

8. Ponikowski P, Voors AA, Anker SD, Bueno H, Cleland JGF, Coats AJS, Falk V, Gonzalez-Juanatey JR, Harjola VP, Jankowska EA, et al. 2016 ESC Guidelines for the diagnosis and treatment of acute and chronic heart failure: The Task Force for the diagnosis and treatment of acute and chronic heart failure of the European Society of Cardiology (ESC)Developed with the special contribution of the Heart Failure Association (HFA) of the ESC. Eur Heart J. 2016;37(27):2129-200.

9. Yancy CW, Jessup M, Bozkurt B, Butler J, Casey DE Jr, Colvin MM, Drazner MH, Filippatos GS, Fonarow GC, Givertz MM, et al. 2017 ACC/AHA/HFSA Focused Update of the 2013 ACCF/AHA Guideline for the Management of Heart Failure: A Report of the American College of Cardiology/American Heart Association Task Force on Clinical Practice Guidelines and the Heart Failure Society of America. Circulation. 2017;136(6):e137-61.

10. Zhang J, Lu CY, Chen $\mathrm{CH}$, Chen HM, Wu SY. Effect of pathologic stages on postmastectomy radiation therapy in breast cancer receiving neoadjuvant chemotherapy and total mastectomy: A Cancer Database Analysis. Breast. 2020;54:70-8.

11. Zhang J, Lu CY, Qin L, Chen HM, Wu SY. Breast-conserving surgery with or without irradiation in women with invasive ductal carcinoma of the breast receiving preoperative systemic therapy: A cohort study. Breast. 2020;54:139-47.

12. Zhang J, Lu CY, Chen HM, Wu SY. Neoadjuvant Chemotherapy or Endocrine Therapy for Invasive Ductal Carcinoma of the Breast With High Hormone Receptor Positivity and Human Epidermal Growth Factor Receptor 2 Negativity. JAMA Netw Open. 2021;4(3):e211785.

13. Liu WC, Liu HE, Kao YW, Qin L, Lin KC, Fang CY, Tsai LL, Shia BC, Wu SY. Definitive radiotherapy or surgery for early oral squamous cell carcinoma in old and very old patients: A propensity-score-matched, nationwide, population-based cohort study. Radiother Oncol. 2020;151:214-21.

14. NCCN Clinical practice guidelines in oncology http://www.nccn.org/professionals/physician_gls/f_guidelines.asp.

15. Hammond ME, Hayes DF, Dowsett M, Allred DC, Hagerty KL, Badve S, Fitzgibbons PL, Francis G, Goldstein NS, Hayes M, et al. American Society of Clinical Oncology/College Of American Pathologists guideline recommendations for immunohistochemical testing of estrogen and progesterone receptors in breast cancer. Journal of clinical oncology: official journal of the American Society of Clinical Oncology. 2010;28(16):2784-95.

16. Charlson M, Szatrowski TP, Peterson J, Gold J. Validation of a combined comorbidity index. J Clin Epidemiol. 1994;47(11):1245-51.

17. Chen JH, Yen YC, Yang HC, Liu SH, Yuan SP, Wu LL, Lee FP, Lin KC, Lai MT, Wu CC, et al. Curative-Intent Aggressive Treatment Improves Survival in Elderly Patients With Locally Advanced Head and Neck Squamous Cell Carcinoma and High Comorbidity Index. Medicine. 2016;95(14):e3268.

18. Lin SH, Wang L, Myles B, Thall PF, Hofstetter WL, Swisher SG, Ajani JA, Cox JD, Komaki R, Liao Z. Propensity score-based comparison of long-term outcomes with 3-dimensional conformal radiotherapy vs intensity-modulated radiotherapy for esophageal cancer. Int J Radiat Oncol Biol Phys. 2012;84(5):1078-85.

19. Austin PC, Stuart EA. Moving towards best practice when using inverse probability of treatment weighting (IPTW) using the propensity score to estimate causal treatment effects in observational studies. Stat Med. 2015;34(28):3661-79.

20. Early Breast Cancer Trialists'. Collaborative G, Darby S, McGale P, Correa C, Taylor C, Arriagada R, Clarke M, Cutter D, Davies C, Ewertz M, et al: Effect of radiotherapy after breast-conserving surgery on 10-year recurrence and 15-year breast cancer death: meta-analysis of individual patient data for 10,801 women in 17 randomised trials. Lancet 2011, 378(9804):170716.

21. Yu JM, Hsieh MC, Qin L, Zhang J, Wu SY. Metformin reduces radiation-induced cardiac toxicity risk in patients having breast cancer. Am J Cancer Res. 2019;9(5):1017-26.

22. Lee CH, Zhang JF, Yuan KS, Wu ATH, Wu SY. Risk of cardiotoxicity induced by adjuvant anthracycline-based chemotherapy and radiotherapy in young and old Asian women with breast cancer. Strahlenther Onkol 2019.

23. Giordano SH, Kuo YF, Freeman JL, Buchholz TA, Hortobagyi GN, Goodwin JS. Risk of cardiac death after adjuvant radiotherapy for breast cancer. J Natl Cancer Inst. 2005;97(6):419-24.

Page 9/18 
24. Darby SC, McGale P, Taylor CW, Peto R. Long-term mortality from heart disease and lung cancer after radiotherapy for early breast cancer: prospective cohort study of about 300,000 women in US SEER cancer registries. Lancet Oncol. 2005;6(8):557-65.

25. Patt DA, Goodwin JS, Kuo YF, Freeman JL, Zhang DD, Buchholz TA, Hortobagyi GN, Giordano SH. Cardiac morbidity of adjuvant radiotherapy for breast cancer. Journal of clinical oncology: official journal of the American Society of Clinical Oncology. 2005;23(30):7475-82.

26. Taylor CW, Bronnum D, Darby SC, Gagliardi G, Hall P, Jensen MB, McGale P, Nisbet A, Ewertz M. Cardiac dose estimates from Danish and Swedish breast cancer radiotherapy during 1977-2001. Radiother Oncol. 2011;100(2):176-83.

27. McGale P, Darby SC, Hall P, Adolfsson J, Bengtsson NO, Bennet AM, Fornander T, Gigante B, Jensen MB, Peto R, et al. Incidence of heart disease in 35,000 women treated with radiotherapy for breast cancer in Denmark and Sweden. Radiother Oncol. 2011;100(2):167-75.

28. Boekel NB, Jacobse JN, Schaapveld M, Hooning MJ, Gietema JA, Duane FK, Taylor CW, Darby SC, Hauptmann M, Seynaeve $\mathrm{CM}$, et al. Cardiovascular disease incidence after internal mammary chain irradiation and anthracycline-based chemotherapy for breast cancer. Br J Cancer. 2018;119(4):408-18.

29. Early Breast Cancer Trialists'. Collaborative G, Peto R, Davies C, Godwin J, Gray R, Pan HC, Clarke M, Cutter D, Darby S, McGale P, et al: Comparisons between different polychemotherapy regimens for early breast cancer: meta-analyses of longterm outcome among 100,000 women in 123 randomised trials. Lancet 2012, 379(9814):432-44.

30. Blum JL, Flynn PJ, Yothers G, Asmar L, Geyer CE Jr, Jacobs SA, Robert NJ, Hopkins JO, O'Shaughnessy JA, Dang CT, et al. Anthracyclines in Early Breast Cancer: The ABC Trials-USOR 06-090, NSABP B-46-I/USOR 07132, and NSABP B-49 (NRG Oncology). Journal of clinical oncology: official journal of the American Society of Clinical Oncology. 2017;35(23):264755 .

31. Zamorano JL, Lancellotti P, Rodriguez Munoz D, Aboyans V, Asteggiano R, Galderisi M, Habib G, Lenihan DJ, Lip GYH, Lyon AR, et al. 2016 ESC Position Paper on cancer treatments and cardiovascular toxicity developed under the auspices of the ESC Committee for Practice Guidelines: The Task Force for cancer treatments and cardiovascular toxicity of the European Society of Cardiology (ESC). Eur Heart J. 2016;37(36):2768-801.

32. Cardinale D, Colombo A, Bacchiani G, Tedeschi I, Meroni CA, Veglia F, Civelli M, Lamantia G, Colombo N, Curigliano G, et al. Early detection of anthracycline cardiotoxicity and improvement with heart failure therapy. Circulation. 2015;131(22):19818.

33. Von Hoff DD, Layard MW, Basa P, Davis HL Jr, Von Hoff AL, Rozencweig M, Muggia FM. Risk factors for doxorubicininduced congestive heart failure. Ann Intern Med. 1979;91(5):710-7.

34. Swain SM, Whaley FS, Ewer MS. Congestive heart failure in patients treated with doxorubicin: a retrospective analysis of three trials. Cancer. 2003;97(11):2869-79.

35. Schwartz RG, McKenzie WB, Alexander J, Sager P, D'Souza A, Manatunga A, Schwartz PE, Berger HJ, Setaro J, Surkin L, et al. Congestive heart failure and left ventricular dysfunction complicating doxorubicin therapy. Seven-year experience using serial radionuclide angiocardiography. Am J Med. 1987;82(6):1109-18.

36. Keefe DL. Trastuzumab-associated cardiotoxicity. Cancer. 2002;95(7):1592-600.

37. Perez EA, Rodeheffer R. Clinical cardiac tolerability of trastuzumab. Journal of clinical oncology: official journal of the American Society of Clinical Oncology. 2004;22(2):322-9.

38. Fiuza M. Cardiotoxicity associated with trastuzumab treatment of HER2+ breast cancer. Adv Ther. 2009;26(Suppl 1):9-17.

39. Mehta LS, Watson KE, Barac A, Beckie TM, Bittner V, Cruz-Flores S, Dent S, Kondapalli L, Ky B, Okwuosa T, et al. Cardiovascular Disease and Breast Cancer: Where These Entities Intersect: A Scientific Statement From the American Heart Association. Circulation. 2018;137(8):e30-66.

40. Roger VL, Weston SA, Redfield MM, Hellermann-Homan JP, Killian J, Yawn BP, Jacobsen SJ. Trends in heart failure incidence and survival in a community-based population. JAMA. 2004;292(3):344-50.

41. Shen L, Jhund PS, Petrie MC, Claggett BL, Barlera S, Cleland JGF, Dargie HJ, Granger CB, Kjekshus J, Kober L, et al. Declining Risk of Sudden Death in Heart Failure. N Engl J Med. 2017;377(1):41-51.

Page $10 / 18$ 
42. Zhang J, Sun M, Chang E, Lu CY, Chen HM, Wu SY. Pathologic response as predictor of recurrence, metastasis, and survival in breast cancer patients receiving neoadjuvant chemotherapy and total mastectomy. Am J Cancer Res.

2020;10(10):3415-27.

43. Zhang J, Qin L, Chen HM, Hsu HC, Chuang CC, Chen D, Wu SY. Overall survival, locoregional recurrence, and distant metastasis of definitive concurrent chemoradiotherapy for cervical squamous cell carcinoma and adenocarcinoma: before and after propensity score matching analysis of a cohort study. Am J Cancer Res. 2020;10(6):1808-20.

44. Zhang J, Lu CY, Chen HM, Wu SY. Pathologic response rates for breast cancer stages as a predictor of outcomes in patients receiving neoadjuvant chemotherapy followed by breast-conserving surgery. Surg Oncol. 2020;36:91-8.

45. Yoo S, Lee HB, Han W, Noh DY, Park SK, Kim WH, Kim JT. Total Intravenous Anesthesia versus Inhalation Anesthesia for Breast Cancer Surgery: A Retrospective Cohort Study. Anesthesiology. 2019;130(1):31-40.

46. Oh TK, Kim HH, Jeon YT. Retrospective analysis of 1-year mortality after gastric cancer surgery: Total intravenous anesthesia versus volatile anesthesia. Acta Anaesthesiol Scand. 2019;63(9):1169-77.

47. Lee JH, Kang SH, Kim Y, Kim HA, Kim BS. Effects of propofol-based total intravenous anesthesia on recurrence and overall survival in patients after modified radical mastectomy: a retrospective study. Korean J Anesthesiol. 2016;69(2):126-32.

48. Enlund M, Berglund A, Ahlstrand R, Wallden J, Lundberg J, Warnberg F, Ekman A, Sjoblom Widfeldt N, Enlund A, Bergkvist L. Survival after primary breast cancer surgery following propofol or sevoflurane general anesthesia-A retrospective, multicenter, database analysis of 6305 Swedish patients. Acta Anaesthesiol Scand. 2020;64(8):1048-54.

49. Makito K, Matsui H, Fushimi K, Yasunaga H. Volatile versus Total Intravenous Anesthesia for Cancer Prognosis in Patients Having Digestive Cancer Surgery. Anesthesiology. 2020;133(4):764-73.

50. Cheng CL, Lee CH, Chen PS, Li YH, Lin SJ, Yang YH. Validation of acute myocardial infarction cases in the national health insurance research database in taiwan. J Epidemiol. 2014;24(6):500-7.

51. Cheng CL, Kao YH, Lin SJ, Lee CH, Lai ML. Validation of the National Health Insurance Research Database with ischemic stroke cases in Taiwan. Pharmacoepidemiol Drug Saf. 2011;20(3):236-42.

52. Lin CC, Lai MS, Syu CY, Chang SC, Tseng FY. Accuracy of diabetes diagnosis in health insurance claims data in Taiwan. J Formos Med Assoc. 2005;104(3):157-63.

\section{Tables}

Table 1

\section{Demographics of patients with breast cancer and heart failure with reduced ejection fraction who received breast conservative surgery in the propensity score-weighted population through inverse probability of treatment weighting (IPTW)}




\begin{tabular}{|c|c|c|c|c|c|c|}
\hline \multirow[b]{3}{*}{ Variable } & & \multicolumn{5}{|c|}{ Propensity score-weighted population } \\
\hline & & \multicolumn{2}{|c|}{$\begin{array}{l}\text { Adjuvant } \\
\text { WBRT } \\
\mathrm{N}=223\end{array}$} & \multicolumn{2}{|c|}{$\begin{array}{l}\text { No adjuvant } \\
\text { WBRT } \\
\mathrm{N}=71\end{array}$} & \multirow[b]{2}{*}{$\begin{array}{l}\text { Standardized } \\
\text { difference }\end{array}$} \\
\hline & & $\mathrm{n}$ & $(\%)$ & $\mathrm{n}$ & $(\%)$ & \\
\hline \multirow[t]{4}{*}{ Age } & Mean (SD) & 62.3 & $(11.4)$ & 63.5 & $(11.6)$ & 0.0311 \\
\hline & $\begin{array}{l}\text { Median (IQR, Q1- } \\
\text { Q3) }\end{array}$ & 63 & $\begin{array}{l}(54- \\
70)\end{array}$ & 63 & $(54-71)$ & \\
\hline & $20-65$ & 167 & $(73.6)$ & 52 & $(73.2)$ & 0.0224 \\
\hline & $>65$ & 60 & $(26.4)$ & 19 & $(26.8)$ & \\
\hline \multirow[t]{2}{*}{ Diagnosis year } & $2008-2012$ & 89 & $(39.2)$ & 28 & $(39.4)$ & 0.0000 \\
\hline & $2013-2017$ & 138 & $(60.8)$ & 43 & $(60.6)$ & \\
\hline \multirow[t]{2}{*}{ CCl score } & 0 & 73 & $(32.7)$ & 22 & $(31.0)$ & 0.0231 \\
\hline & $\geq 1$ & 150 & $(67.3)$ & 49 & $(69.0)$ & \\
\hline \multirow[t]{3}{*}{ Differentiation } & I & 44 & $(19.7)$ & 16 & $(22.5)$ & - \\
\hline & II & 112 & $(50.2)$ & 34 & $(47.9)$ & 0.0566 \\
\hline & III & 67 & $(30.0)$ & 21 & $(29.6)$ & 0.0452 \\
\hline \multirow[t]{2}{*}{ AJCC clinical stage } & 1 & 112 & $(50.2)$ & 33 & $(46.5)$ & 0.0831 \\
\hline & II-III & 111 & $(49.8)$ & 38 & $(53.5)$ & \\
\hline \multirow[t]{3}{*}{ AJCC pathologic stage } & I & 109 & $(48.9)$ & 34 & $(47.9)$ & - \\
\hline & II & 97 & $(43.5)$ & 32 & $(45.1)$ & 0.0242 \\
\hline & III & 18 & $(8.1)$ & 6 & $(8.5)$ & 0.0170 \\
\hline \multirow[t]{2}{*}{ pT } & pT1 & 137 & $(61.4)$ & 41 & $(57.7)$ & 0.0737 \\
\hline & pT2-4 & 86 & $(38.6)$ & 30 & $(42.3)$ & \\
\hline \multirow[t]{2}{*}{$\mathrm{pN}$} & pNO & 164 & $(73.5)$ & 49 & $(69.0)$ & 0.0705 \\
\hline & $\mathrm{pN} 1-3$ & 59 & $(26.5)$ & 22 & $(31.0)$ & \\
\hline Hypertension & & 161 & $(72.2)$ & 50 & $(70.4)$ & 0.0584 \\
\hline Ischemic heart disease & & 88 & $(39.5)$ & 27 & $(38.0)$ & 0.0352 \\
\hline Valvular disease & & 17 & $(7.6)$ & 6 & $(8.5)$ & 0.0276 \\
\hline Cardiomyopathy & & 71 & $(31.8)$ & 23 & $(32.4)$ & 0.0381 \\
\hline $\begin{array}{l}\text { Arrhythmias and conduction } \\
\text { disorders }\end{array}$ & & 6 & $(2.7)$ & 2 & $(2.8)$ & 0.0114 \\
\hline Diabetes mellitus & & 76 & $(34.1)$ & 27 & $(38.0)$ & 0.0779 \\
\hline Chemotherapy with anthracycline & & 103 & $(46.2)$ & 34 & $(47.9)$ & 0.0072 \\
\hline Hormone receptor positive & & 109 & $(48.9)$ & 35 & $(49.3)$ & 0.0089 \\
\hline Trastuzumab use & & 21 & $(9.3)$ & 7 & $(9.9)$ & 0.0131 \\
\hline Nodal surgery & ALND & 139 & $(61.2)$ & 40 & $(56.3)$ & 0.0618 \\
\hline
\end{tabular}




\begin{tabular}{|c|c|c|c|c|c|c|}
\hline & & \multicolumn{5}{|c|}{ Propensity score-weighted population } \\
\hline & & \multicolumn{2}{|c|}{$\begin{array}{l}\text { Adjuvant } \\
\text { WBRT } \\
\mathrm{N}=223\end{array}$} & \multicolumn{2}{|c|}{$\begin{array}{l}\text { No adjuvant } \\
\text { WBRT } \\
\mathrm{N}=71\end{array}$} & \multirow[b]{2}{*}{$\begin{array}{l}\text { Standardized } \\
\text { difference }\end{array}$} \\
\hline \multirow[t]{2}{*}{ Variable } & & $\mathrm{n}$ & $(\%)$ & $\mathrm{n}$ & $(\%)$ & \\
\hline & SLNB & 84 & $(38.8)$ & 31 & $(43.7)$ & \\
\hline \multirow[t]{2}{*}{ Hospital level } & Academic center & 110 & $(49.3)$ & 35 & $(49.3)$ & 0.0000 \\
\hline & $\begin{array}{l}\text { Nonacademic } \\
\text { center }\end{array}$ & 113 & $(50.7)$ & 36 & $(50.7)$ & \\
\hline \multirow[t]{4}{*}{ Income } & $<$ NTD 18,000 & 65 & $(29.1)$ & 20 & $(28.2)$ & - \\
\hline & $\begin{array}{l}\text { NTD 18,000- } \\
24,000\end{array}$ & 74 & $(33.2)$ & 23 & $(32.4)$ & 0.0231 \\
\hline & $\begin{array}{l}\text { NTD 24,000- } \\
36,000\end{array}$ & 40 & $(17.9)$ & 12 & $(16.9)$ & 0.0143 \\
\hline & $>$ NTD 36,000 & 44 & $(19.7)$ & 16 & $(22.5)$ & 0.0712 \\
\hline \multicolumn{7}{|c|}{$\begin{array}{l}\text { IQR, interquartile range; SD, standard deviation; AJCC, American Joint Committee on Cancer; Her-2, Human Epidermal } \\
\text { Growth Factor Receptor-2; WBRT, whole-breast radiotherapy; CCI, Charlson comorbidity index; T, tumor; N, nodal; } \mathrm{pT} \text {, } \\
\text { pathologic tumor stage; pN, pathologic nodal stage; ALND, axillary lymph node dissection; SNLB, sentinel lymph node } \\
\text { biopsy; NTD, New Taiwan dollar }\end{array}$} \\
\hline
\end{tabular}

Table 2

Multivariate analysis of propensity score-weighted population with breast cancer and heart failure with reduced ejection fraction receiving breast conservative surgery 
All-cause death Local recurrence Distant metastasis

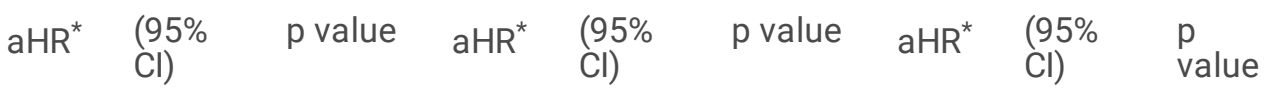

\begin{tabular}{|c|c|c|c|c|c|c|c|c|c|c|}
\hline Adjuvant WBRT & No & Ref & & 0.0494 & Ref & & 0.0028 & Ref & & 0.0007 \\
\hline & Yes & 0.58 & $\begin{array}{l}(0.33- \\
1.00)\end{array}$ & & 0.25 & $\begin{array}{l}(0.10- \\
0.62)\end{array}$ & & 0.29 & $\begin{array}{l}(0.14- \\
0.60)\end{array}$ & \\
\hline \multirow[t]{2}{*}{ Age } & $20-65$ & Ref & & 0.0002 & Ref & & 0.5433 & Ref & & 0.4948 \\
\hline & $>65$ & 1.34 & $\begin{array}{l}(1.18- \\
3.26)\end{array}$ & & 1.18 & $\begin{array}{l}(0.63- \\
1.95)\end{array}$ & & 1.70 & $\begin{array}{l}(0.65- \\
1.95)\end{array}$ & \\
\hline \multirow[t]{2}{*}{ Diagnosis year } & $2009-2012$ & Ref & & 0.4611 & Ref & & 0.1881 & Ref & & 0.8695 \\
\hline & $2013-2017$ & 0.81 & $\begin{array}{l}(0.73- \\
1.42)\end{array}$ & & 0.74 & $\begin{array}{l}(0.48- \\
1.16)\end{array}$ & & 0.94 & $\begin{array}{l}(0.58- \\
1.86)\end{array}$ & \\
\hline \multirow[t]{2}{*}{ CCl score } & 0 & Ref & & 0.0401 & Ref & & 0.5281 & Ref & & 0.8993 \\
\hline & $\geq 1$ & 1.14 & $\begin{array}{l}(1.08- \\
1.72)\end{array}$ & & 1.05 & $\begin{array}{l}(0.73- \\
1.74)\end{array}$ & & 1.06 & $\begin{array}{l}(0.44- \\
1.58)\end{array}$ & \\
\hline Hypertension & Yes & 1.17 & $\begin{array}{l}(0.69- \\
1.96)\end{array}$ & 0.5656 & 0.95 & $\begin{array}{l}(0.60- \\
1.50)\end{array}$ & 0.8313 & 0.98 & $\begin{array}{l}(0.68- \\
1.42)\end{array}$ & 0.9253 \\
\hline $\begin{array}{l}\text { Ischemic heart } \\
\text { diseases }\end{array}$ & Yes & 1.32 & $\begin{array}{l}(0.81- \\
2.15)\end{array}$ & 0.2725 & 0.75 & $\begin{array}{l}(0.48- \\
1.21)\end{array}$ & 0.7022 & 0.95 & $\begin{array}{l}(0.76- \\
1.55)\end{array}$ & 0.2315 \\
\hline Valvular disease & Yes & 1.15 & $\begin{array}{l}(0.75- \\
2.11)\end{array}$ & 0.2144 & 1.00 & $\begin{array}{l}(0.69- \\
1.45)\end{array}$ & 0.9866 & 0.96 & $\begin{array}{l}(0.49- \\
1.90)\end{array}$ & 0.9081 \\
\hline Cardiomyopathy & Yes & 1.13 & $\begin{array}{l}(0.88- \\
1.65)\end{array}$ & 0.1312 & 0.77 & $\begin{array}{l}(0.45- \\
1.82)\end{array}$ & 0.3404 & 0.92 & $\begin{array}{l}(0.63- \\
2.57)\end{array}$ & 0.5322 \\
\hline $\begin{array}{l}\text { Arrhythmias and } \\
\text { conduction } \\
\text { disorders }\end{array}$ & Yes & 1.08 & $\begin{array}{l}(0.88- \\
1.46)\end{array}$ & 0.1786 & 0.89 & $\begin{array}{l}(0.53- \\
2.67)\end{array}$ & 0.2762 & 0.76 & $\begin{array}{l}(0.41- \\
1.39)\end{array}$ & 0.3174 \\
\hline Diabetes & Yes & 1.06 & $\begin{array}{l}(0.84- \\
1.14)\end{array}$ & 0.3127 & 0.91 & $\begin{array}{l}(0.67- \\
1.20)\end{array}$ & 0.4714 & 0.68 & $\begin{array}{l}(0.52- \\
1.28)\end{array}$ & 0.8784 \\
\hline \multirow[t]{2}{*}{ pT } & pT1 & Ref & & 0.0329 & Ref & & 0.0468 & Ref & & 0.2525 \\
\hline & pT2-4 & 1.33 & $\begin{array}{l}(1.05- \\
2.34)\end{array}$ & & 1.73 & $\begin{array}{l}(1.01- \\
1.71)\end{array}$ & & 1.56 & $\begin{array}{l}(0.73- \\
3.32)\end{array}$ & \\
\hline \multirow[t]{2}{*}{$\mathrm{pN}$} & pNO & Ref & & 0.0026 & Ref & & 0.0198 & Ref & & 0.0299 \\
\hline & $\mathrm{pN} 1-3$ & 2.48 & $\begin{array}{l}(1.37- \\
4.47)\end{array}$ & & 1.82 & $\begin{array}{l}(1.43- \\
4.53)\end{array}$ & & 1.75 & $\begin{array}{l}(1.31- \\
2.84)\end{array}$ & \\
\hline \multirow[t]{3}{*}{ Differentiation } & I & Ref & & 0.0005 & Ref & & 0.0001 & Ref & & 0.0001 \\
\hline & II & 1.58 & $\begin{array}{l}(1.15- \\
2.17)\end{array}$ & & 2.06 & $\begin{array}{l}(1.71- \\
3.27)\end{array}$ & & 2.02 & $\begin{array}{l}(1.58- \\
3.04)\end{array}$ & \\
\hline & III & 1.73 & $\begin{array}{l}(1.26- \\
2.36)\end{array}$ & & 2.16 & $\begin{array}{l}(1.89- \\
3.46)\end{array}$ & & 2.94 & $\begin{array}{l}(1.69- \\
3.61)\end{array}$ & \\
\hline $\begin{array}{l}\text { Chemotherapy } \\
\text { with } \\
\text { anthracycline }\end{array}$ & Yes & 0.98 & $\begin{array}{l}(0.30- \\
182)\end{array}$ & 0.1411 & 0.78 & $\begin{array}{l}(0.31- \\
1.96)\end{array}$ & 0.1422 & 0.72 & $\begin{array}{l}(0.59- \\
1.87)\end{array}$ & 0.3855 \\
\hline $\begin{array}{l}\text { Hormone } \\
\text { receptor positive }\end{array}$ & Yes & 0.68 & $\begin{array}{l}(0.52- \\
0.88)\end{array}$ & 0.0042 & 0.66 & $\begin{array}{l}(0.50- \\
0.86)\end{array}$ & 0.0024 & 0.59 & $\begin{array}{l}(0.32- \\
0.75)\end{array}$ & 0.0013 \\
\hline Trastuzumab & Yes & 1.03 & $(0.42-$ & 0.9547 & 1.65 & $(0.73-$ & 0.9085 & 1.16 & $(0.73-$ & 0.5321 \\
\hline
\end{tabular}


use

2.51)

3.74)

1.83)

\begin{tabular}{|c|c|c|c|c|c|c|c|c|c|c|}
\hline Nodal surgery & ALND & Ref & & 0.8831 & Ref & & 0.3162 & Ref & & 0.3488 \\
\hline & SLNB & 1.17 & $\begin{array}{l}(0.96- \\
1.25)\end{array}$ & & 1.29 & $\begin{array}{l}(0.84- \\
2.21)\end{array}$ & & 1.39 & $\begin{array}{l}(0.70- \\
2.74)\end{array}$ & \\
\hline \multirow[t]{2}{*}{ Hospital level } & $\begin{array}{l}\text { Medical } \\
\text { centers }\end{array}$ & Ref & & 0.1667 & Ref & & 0.4441 & Ref & & 0.7028 \\
\hline & $\begin{array}{l}\text { Nonmedical } \\
\text { centers }\end{array}$ & 1.08 & $\begin{array}{l}(0.81- \\
1.24)\end{array}$ & & 0.92 & $\begin{array}{l}(0.61- \\
2.57)\end{array}$ & & 0.92 & $\begin{array}{l}(0.71- \\
1.49)\end{array}$ & \\
\hline \multirow[t]{4}{*}{ Income } & $\begin{array}{l}<\text { NTD } \\
18,000\end{array}$ & Ref & & 0.4221 & Ref & & 0.8651 & Ref & & 0.7629 \\
\hline & $\begin{array}{l}\text { NTD } \\
18,000- \\
24,000\end{array}$ & 1.34 & $\begin{array}{l}(0.61- \\
2.93)\end{array}$ & & 1.22 & $\begin{array}{l}(0.69- \\
2.14)\end{array}$ & & 1.17 & $\begin{array}{l}(0.69- \\
1.96)\end{array}$ & \\
\hline & $\begin{array}{l}\text { NTD } \\
24,000- \\
36,000\end{array}$ & 1.53 & $\begin{array}{l}(0.88- \\
2.65)\end{array}$ & & 1.37 & $\begin{array}{l}(0.73- \\
2.45)\end{array}$ & & 1.53 & $\begin{array}{l}(0.78- \\
2.18)\end{array}$ & \\
\hline & $\begin{array}{l}>\text { NTD } \\
36,000\end{array}$ & 1.68 & $\begin{array}{l}(0.92- \\
3.09)\end{array}$ & & 1.73 & $\begin{array}{l}(0.94- \\
2.96)\end{array}$ & & 2.14 & $\begin{array}{l}(0.83- \\
3.25)\end{array}$ & \\
\hline
\end{tabular}

aHR, adjusted hazard ratios; Cls, confidence intervals; HR, hormone receptor; Her-2, human epidermal growth factor receptor2; WBRT, whole-breast radiotherapy; CCl, Charlson comorbidity index; T, tumor; N, nodal; $\mathrm{PT}$, pathologic tumor stage; $\mathrm{pN}$, pathologic nodal stage; ALND, axillary lymph node dissection; SNLB, sentinel lymph node biopsy; ref, reference group; NTD, New Taiwan dollar

*All covariates mentioned in Table 2 were adjusted.

\section{Figures}




\section{Overall Survival}

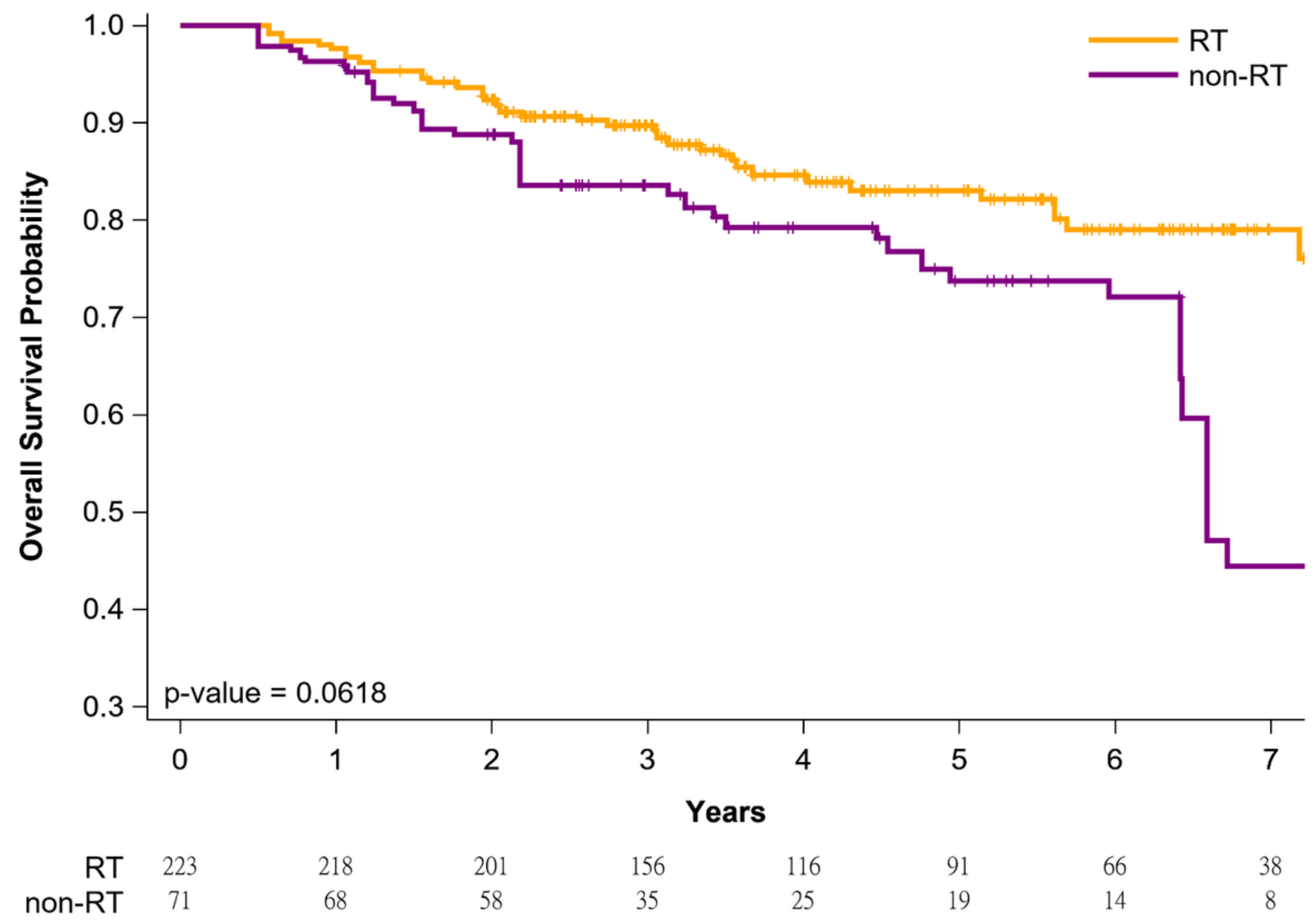

\section{Figure 1}

Kaplan-Meier overall survival curves of propensity score-weighted population with breast cancer and heart failure with reduced ejection fraction receiving breast conservative surgery 


\section{LRR-Free Survival}

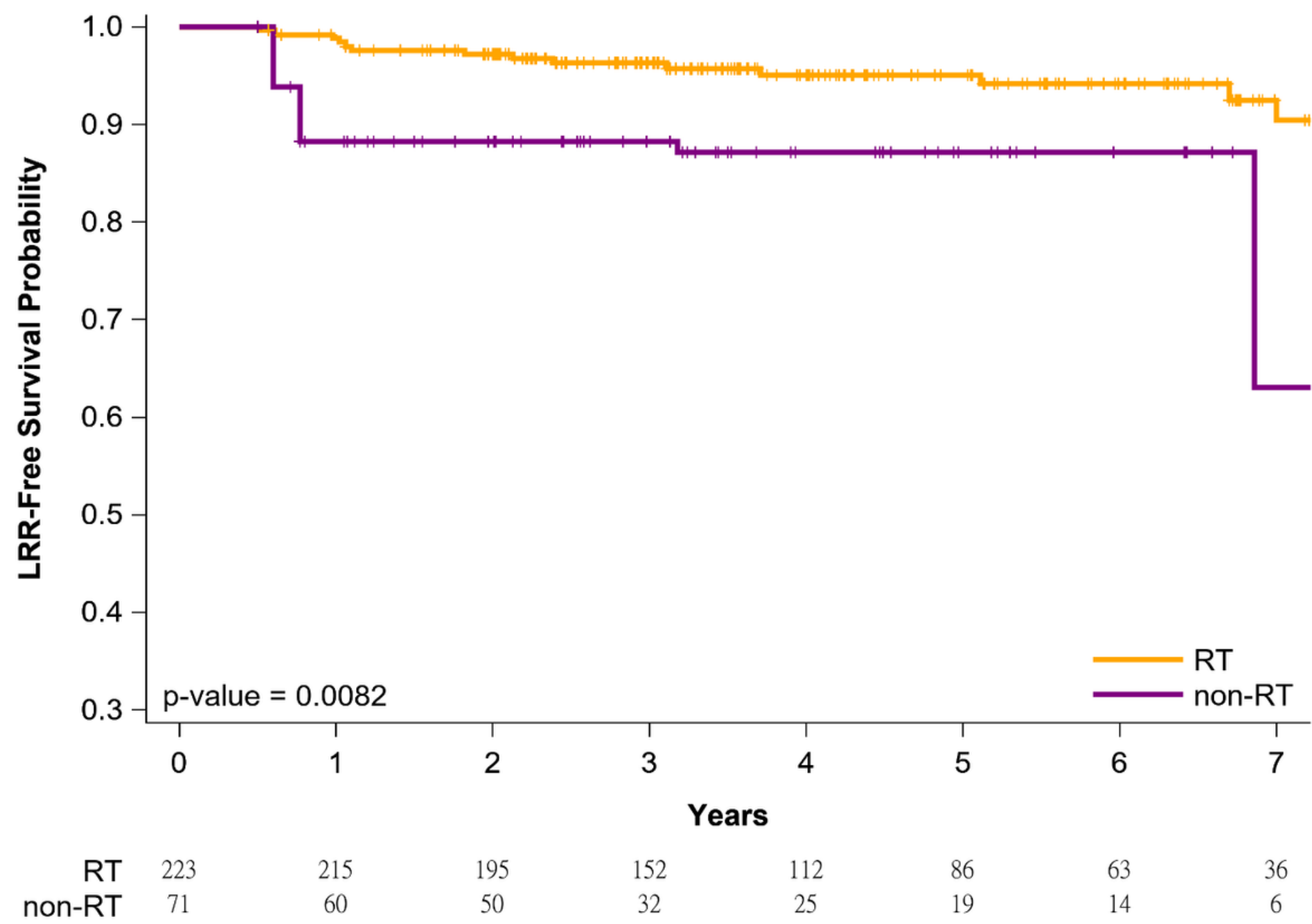

\section{Figure 2}

Kaplan-Meier locoregional recurrence-free survival curves of propensity score-weighted population with breast cancer and heart failure with reduced ejection fraction receiving breast conservative surgery 


\section{Distant metastasis-Free Survival}

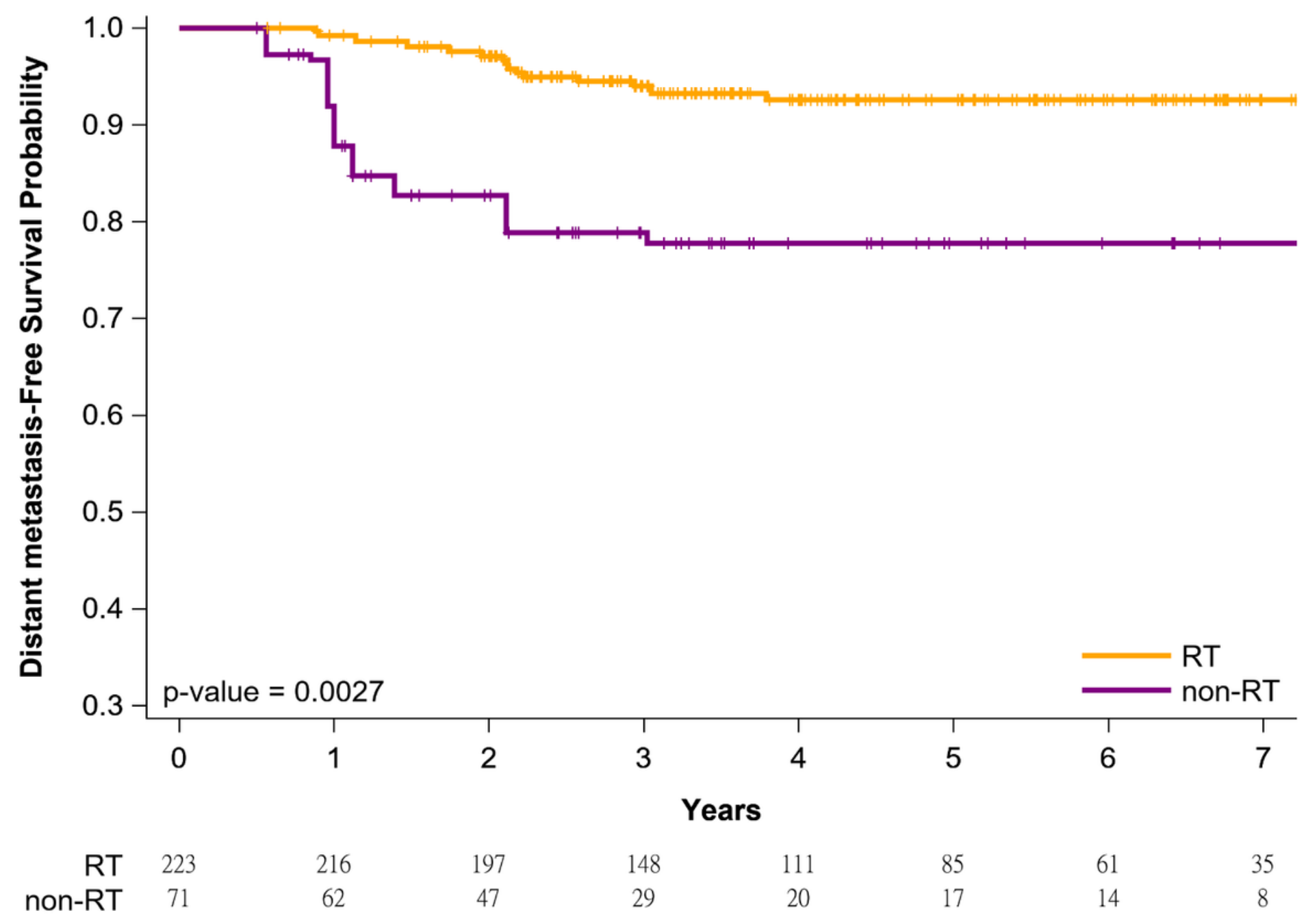

\section{Figure 3}

Kaplan-Meier distant metastasis-free survival curves of propensity score-weighted population with breast cancer and heart failure with reduced ejection fraction receiving breast conservative surgery 